\title{
Ethical Dilemmas Related to Foetal Diagnosis and Foetocide
}

\author{
Ermos Nicolaou ${ }^{1,2,3}$ \\ ${ }^{1}$ Division of Maternal and Foetal Medicine, University of the Witwatersrand, Johannesburg, South Africa \\ ${ }^{2}$ Chris Hani Baragwanath Academic Hospital, Johannesburg, South Africa \\ ${ }^{3}$ Morningside Mediclinic, Johannesburg, South Africa
}

Email address:

Ermos.Nicolaou@wits.ac.za

\section{To cite this article:}

Ermos Nicolaou. Ethical Dilemmas Related to Foetal Diagnosis and Foetocide. Journal of Gynecology and Obstetrics. Vol. 9, No. 4, 2021, pp. 120-124. doi: 10.11648/j.jgo.20210904.15

Received: July 20, 2021; Accepted: August 5, 2021; Published: August 18, 2021

\begin{abstract}
Ethics is an essential dimension of obstetrics and gynaecology and helps balance beneficence and autonomybased obligations with professional conscience ensuring respect for the pregnant woman's autonomy. The Law defines what can be offered in our country and guides the obstetrician as well as the parents. In South Africa termination of pregnancy is legal. A woman can request termination of her pregnancy up until 12 weeks if she chooses so. The South African law allows termination of a pregnancy up to 20 weeks and beyond 20 weeks if there are significant reasons for this to be requested or offered. The question of what foetal abnormalities are considered significant and therefore should be considered for termination has led to ongoing discussions and debates in various levels of medical and legal societies. The obstetrician has the right to exercise his or her own autonomy in dealing with these situations. Exercise of autonomy by a patient cannot justifiably oblige a physician to act in a way that is unacceptable as a matter of his/her individual conscience. Citing case laws, the Courts in the country are asked to decide on "wrongful birth"- which would require a Court to determine whether a child should have been born. The South African Constitutional Court in a recent ruling determined that "this goes to the heart of what it is to be human, something that should not be asked of the law". Medical and legal societies need to work together and help guide our doctors, our patients and society as to what is ethical and acceptable practice in complex situations where children's genetic and structural abnormalities alone perhaps should not decide their entire destiny.
\end{abstract}

Keywords: Ethical Dilemmas, Foetal Diagnosis, Foetocide

\section{Introduction}

Increasing accessibility to the internet has resulted in patients being more informed about their health, more aware of their rights when consulting with a doctor and more demanding in seeking answers about their pregnancies.

This is an international phenomenon and South Africa is not unique in this globalization of medical information and medical care, and seeking expert advice from someone who may be in a different continent is a daily phenomenon.

Medical practitioners, more than ever before, need to be well informed about new trends in medical care in particular in the developed world, but also need to be aware of their own rights as doctors.

The fear of litigation, particularly in Obstetrics, makes matters more complex and should not be underestimated.

Doctors need to practice medicine that is of a good standard, is safe, and is morally acceptable to the patient and their families, the medical fraternity and the law of the country.

To achieve this one has to go back to the very foundation of the medical profession, and practice within the framework of the principles of medical ethics:

\section{Principles of Ethics}

\subsection{The Obligation to Practice}

1) Beneficence

Enhance wellbeing by maximizing benefits.

2) Non Maleficence 
Minimize or cause no harm.

3) Respect for Autonomy

Respect and facilitate choices of autonomous persons.

4) Distributive justice

Treat equals equally [1].

\subsection{Beneficence}

The intention to try and do what is good for the patient even if this may be in conflict with the patient's autonomy.

\subsection{Non-maleficence}

First do no harm: Any decision regarding therapy must be balanced in terms of its risks as well as its benefits.

\section{Autonomy}

An adult with the capacity to make decisions may decide what may be done to her body. This includes refusal of any treatment.

Even if this refusal seems inappropriate it does not counter ethical or legal norms.

The physician has no authority to assess the worth or meaning to the pregnant woman of her own non-health related interests unless there is reliable evidence of clinical deficits in her decision making process.

In Obstetrics we are in the unique situation where we manage two patients at once: Before a practitioner embarks on managing a pregnant patient he/she needs to familiarize $\mathrm{him} /$ herself with the concept of the foetus as a patient, the autonomy of the mother and the conditional, separate autonomy of her foetus.

The foetus does not possess an independent moral status, has no perspective on its interests or on its values and beliefs and there can be no autonomy based obligations to any foetus

However, the fact that the foetus has no rights should not be an obstacle to becoming a patient. The foetus becomes a patient when the mother presents her foetus for medical care.

The concept of a foetus as a patient guides the obstetrician, helps to balance beneficence and autonomy based obligations with professional conscience and at the same time respects the pregnant woman's autonomy.

In addition to the general concept of a foetus as a patient, there are other, equally important factors that need to be addressed when managing a mother with her unborn baby:

\section{Viability of a Foetus in General}

Viability means the capacity of a foetus to survive outside the woman's womb with or without technical support.

Viability is usually seen as the point at which abortion is no longer generally acceptable or tolerated by society. In other words many people feel that viability is a morally significant point in pregnancy.

Viability should not be viewed as an exclusively biological property of the foetus but as combination of biological and technological factors.

\section{Argument Against the Use of Moral Significance of Viability}

If we consider that the rights of a foetus increase at the point of viability, most foetuses in the developing world gain those rights long after most foetuses in the developed world.

A foetus of 24 weeks in the developing world might have no moral or legal rights because it has not reached viability, whereas a foetus in the developed world would have a legal or moral right to life.

The likelihood of keeping a premature baby alive varies enormously depending on the healthcare services available in the region, country or continent.

A very premature baby in a rural area within the developing world is unlikely to survive and therefore viability in one place means something quite different from viability in another.

This, however, is not unique to obstetrics: a patient with massive internal injuries and uncontrolled, internal bleeding is viable if he has access to surgery, but not viable if such access is not available. This is the so-called Technological Factor.

Possibly, the best way to reach a decision regarding foetocide and termination of pregnancy should be based on the circumstances a woman finds herself in, her ability to care for her child and the impact that the child's disability will have on her and the family.

Linked with this should be a judgement of the suffering that the child will experience.

\section{Viability with Antenatal Abnormalities}

The following questions aim to help define the severity of a congenital abnormality and reach a consensus with regards to the best way forward:

Is the condition or abnormality compatible with life?

Will life-time aid be required?

What is the probable life-span?

Is the condition correctible?

What are the socio-economic circumstances of the patient?

The answers to the above questions should not be the doctors alone.

Equally important in debating some of the answers is the law of the country.

\section{Our Constitution}

Our constitution is clear on the subject of viability and access to medical care; some points are, however, open to interpretation.

Our constitution states

"Everyone has the right to have access to health care services"

"No one may be refused emergency medical treatment" Should this be applicable to a newborn baby with a weight of less than 500 grams? If yes, for how long and at what expense? 
"The state must take reasonable legislative and other measures within its available resources to achieve progressive realization of these rights". The key word is "available resources". A poor country with limited resources cannot look after its disabled people as well as a rich country.

"The child's best interests are of paramount importance".

Key factors for consideration are:

1. Preservation and restoration of function

2. Quality as well as extent of life

3. Possibility of developing/ regaining the capacity of self determination

4. Relief of suffering

What if the extent of the malformation and the suffering of the baby and its mother are significant enough to justify a medical intervention to terminate the pregnancy.

Termination of a pregnancy is allowed in some countries, is conditionally allowed in some countries and is prohibited in many others, mainly on religious grounds. More rarely, even euthanasia is allowed to be performed on a newborn with severe abnormalities.

In South Africa the Termination of the Pregnancy Act-Act 92 of 1996, and 2005 states:

Termination of a pregnancy can be offered

1. Upon request of a woman during the first 12 weeks of pregnancy;

2. From the 13th to the 20th week of pregnancy if a medical practitioner, after consultation with the woman, is of the opinion that

a. Continuation of the pregnancy poses a risk to the woman's physical or mental health

b. A substantial risk exists that the foetus would suffer from a severe physical or mental abnormality

Of course a point that is open to interpretation and legal arguments is the word "substantial". What risk is substantial?

c. The pregnancy resulted from rape or incest

d. The continued pregnancy would significantly affect the social or economic circumstances of the woman

3. Termination of a pregnancy can be offered after the 20th week of pregnancy if a medical practitioner, after consultation with another medical practitioner or midwife, is of the opinion that continued pregnancy would
a. Endanger the woman's life
b. Result in severe malformation of the foetus

c. Would pose risk of injury to the foetus $[2,3]$

What constitutes a severe malformation is sometimes open to discussion and should be debated within a team of practitioners from various disciplines.

Some examples of non-viable malformations are:

a. Trisomy 13

b. Trisomy 18

c. Bilateral renal agenesis

d. Thanatophoric dysplasia

e. Holoprosencephaly

f. Anencephaly

g. Other severe brain abnormalities

h. Severe cardiac abnormalities

With these abnormalities death is almost certain and therefore, in beneficence-based-judgment, foetocide is acceptable.

\section{What Constitutes a "Not-So-Severe" Abnormality}

Some abnormalities are compatible with life and as such need to be debated. A decision regarding a potential termination of the pregnancy with or without foetocide is far more complex. Here one argument against termination of the pregnancy is that society has a justice-based obligation to look after its disabled and to maximize their potential.

Examples of relatively common abnormalities in this category are:

Down's syndrome

Spina Bifida

Isolated hydrocephalus

Diaphragmatic hernia

Achondroplasia

Most repairable cardiac abnormalities [4, 5]

\section{Ethical Issues with Embryo Reduction in Multiple Pregnancies}

The intent of the mother to have an embryo reduction is different from having an abortion. A patient, who requests an Abortion, wishes not to have a pregnancy.

A patient who wishes to have a Selective Embryo Reduction wishes to have a more successful pregnancy by optimizing the chances of survival of the remaining embryos.

The aim of embryo reduction is the live birth of one or more foetuses with minimal neonatal morbidity or mortality:

It is usually offered to quadruplet and higher order multiples where foetal reduction may improve the outcome of the survivors.

More recently, with advancements in Assisted Reproductive Techniques, multiple pregnancies are becoming more common, with increased risks of severe prematurity and handicap if allowed to continue without selective embryo reduction.

Selective termination of multifetal pregnancies may be required to achieve a:

Live birth with minimal neonatal morbidity or mortality of the remaining surviving foetuses.

Live birth of one or more infants without abnormalities detected antenatally.

In cases involving twins and triplets, Fetal Termination for the Preservation of Pregnancy (FTPP) is not comparably justifiable because it does not increase the likelihood of having a healthy baby to take home.

Data on FTPP in twin and triplet gestations show outcomes are no better than the outcomes in twin and triplet gestations when FTPP is not performed. [4-7]

With regards to termination of the pregnancy at or after 20 weeks, the law states, that it is permissible for a patient to have a termination after 20 weeks provided there is an 
abnormality that is severe.

The law permits termination beyond 20 weeks but the issue of foetal viability (after 24 weeks) is not addressed. [2, 3]

The issue of termination of a "previable foetus" before 24 weeks and a "viable foetus" after 24 weeks needs to be addressed separately: A foetus that reaches 24 weeks and beyond or the estimated foetal weight is $>500 \mathrm{~g}$, is able to live outside the uterus. The foetus becomes "viable". If a decision is taken to have a termination of the pregnancy after 24 weeks, although legally permitted, a foetocide should have to be performed before delivery of the foetus. In other words the foetus dies in utero after injection of Potassium Chloride, and is not alive at delivery. Many medical practitioners find it morally difficult to perform a foetocide and the decision to have a termination after 24 weeks becomes morally complex. [6-10, 15]

Trisomy 21 (Down's syndrome) deserves a special discussion because it is relatively common and if missed may lead to litigation against health care practitioners.

Early diagnosis of Downs's syndrome is key to avoid late termination (after $24 \mathrm{w}$ ) and the psychological trauma that accompanies such late terminations.

It is strongly recommended and indeed it is currently common practice for patients to book to see their gynaecologists early and go through the process of early pregnancy evaluation and assessment. If the screening for Down's syndrome is positive (these risks are well defined in the literature), further discussion and counselling needs to take place to discuss the severity of the condition and the available tests to confirm the diagnosis. Termination of the pregnancy after 24 weeks (after the foetus becomes viable) for Down's syndrome in an otherwise structurally normal foetus may not be readily available because an increasing number of doctors feel uneasy to terminate such pregnancies. One of the reasons is the need to perform a foetocide before the termination takes place. The law does not prohibit such terminations if there are valid medical reasons.

It is challenging in a country such as ours to assess every pregnancy before 24 weeks because often patients may not be able to see their doctor timeously (both in the public and private sector).

The emotional and psychological stress after a diagnosis of any abnormality may be severe and extensive counselling should be readily available to explain the condition and look at various options regarding the way forward. $[6,14]$

\section{Foetocide}

Defined as the destruction of the embryo or foetus in the uterus and can be performed by means such as injection of potassium chloride, lignocaine or ligation of the umbilical cord. [12]

\section{Individual Conscience and TOP}

The obstetrician has the right to exercise his or her own autonomy in dealing with these situations.

Exercise of autonomy by a patient cannot justifiably oblige a physician to act in a way that is unacceptable as a matter of his/her individual conscience.

The physician should explain why the service cannot be offered by him or herself.

Should display respect for the integrity of the patient's values or beliefs.

Emphasize that because he/she is not able to provide the service, that the patient is not acting in a morally unjustified manner and arrange when possible a direct referral to a colleague who is able to provide the service. [7]

\section{Case Examples}

a. Termination of pregnancy

b. Contraception

A doctor cannot be forced to provide these services so long as the objection does not contravene relevant anti-discrimination laws and does not compromise the clinical care of the patient.

The same doctor must provide any other care needed for these women.

Such as evacuation for retained products after Termination of the Pregnancy or PID (Pelvic Inflammatory Disease) following insertion of an Intra Uterine Contraceptive Device. [9]

\section{Conclusion}

In conclusion the concept of a foetus as a patient and the issue of foetocide should not be seen in isolation but together with the study of ethics and the law of the country.

Ethics is an essential dimension of obstetrics and gynaecology and helps balancing beneficence and autonomy based obligations with professional conscience ensuring respect for the pregnant woman's autonomy.

The Law defines what can be offered in our country and guides the obstetrician as well as the parents.

Children's genetic and structural abnormalities alone should not decide their entire destiny. Much depends on how much and what kind of health care, education, housing, food and love they are provided with.

No matter how genetically perfect a child is born, if that child is put into an uncaring environment, she or he will probably not develop nearly as well as a normal or even lessthan-normal child reared in a caring environment.

Our task is to help create a just society in which all mothers are safe, every pregnancy should be a wanted one and the children should be provided with every opportunity to develop, progress and thrive $[11,13]$.

\section{References}

[1] Beauchamp T, Childress J. Principles of Biomedical Ethics. 7. New York: Oxford University Press; 2013.

[2] Choice on Termination of Pregnancy Act 92 of 1996. Section 5 (3) and 5 (2). 
[3] Constitution of the Republic of South Africa, 1996 - Chapter 2 (27-28): Bill of Rights.

[4] Chevernak FA, McCullough LB. The Ethics of Feticide. Fet Mat Med Rev. 2007; 18: 289-309.

[5] Nicolaides, KH, Campbell, S, Gabbe, SG, Guidetti, R. Ultrasound Screening for Spina Bifida: Cranial and Cerebral Signs. Lancet 1986; 2: 72-74.

[6] Evans, MI, Dommergues, M, Wapner, R, Lynch, L, Dumez, Y, Goldberg, JD et al. Efficacy of transabdominal multifetal pregnancy reduction: collaborative experience among the world's largest centers. Obstet Gynecol 1993; 82: 61-67.

[7] Evans, MI, Johnson, MP, Quintero, RA, Fletcher, JC. Ethical issues surrounding multifetal pregnancy reduction and selective termination. Clin Perinat 1996; 23: 437-51.

[8] Keymanthri Moodley. The ethics of Feticide and late termination of pregnancy. South African Journal of Obstetrics and Gynaecology 200814 (1): 28.
[9] K Moodley. Ethics; Feticide; Late termination of pregnancy $\mathrm{O}$ \& G Forum Vol. 18 (3) 2008: pp. 93-95.

[10] Chervenak, FA, McCullough, LB. The limits of viability. 1997; J Perinat Med 25: 418-20.

[11] Rosemarie Tong Department of Philosophy. University of North Carolina at Charlotte, Charlotte, USA Cambridge University Press 2002; Chapter 5: 87-100.

[12] Fetal Pain: A Systematic Multidisciplinary Review of the Evidence. JAMA 2005; 294: 947-954.

[13] Ethical issues in Maternal and Fetal Medicine, Donna L Dickenson, Cambridge University press 2002.

[14] Genome: the Autobiography of a Species in 23 Chapters. Matt Ridley 2002.

[15] The Care of Women requesting induced abortion, Evidencebased Clinical Guideline Number 7, RCOG, 2004. 